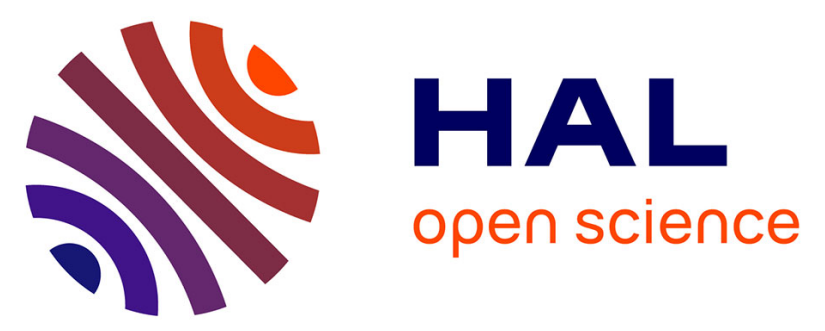

\title{
Impact of an educational intervention on ankle-brachial index performance among medical students and fidelity assessment at month-6
}

Loukman Omarjee, Céline Donnou, Ségolène Chaudru, Clara Locher, Eunice Paul, Marie Charasson, Chadi Mauger, Vincent Jaquinandi, Olivier Stivalet, Guillaume Mahé

\section{To cite this version:}

Loukman Omarjee, Céline Donnou, Ségolène Chaudru, Clara Locher, Eunice Paul, et al.. Impact of an educational intervention on ankle-brachial index performance among medical students and fidelity assessment at month-6. Annals of Vascular Surgery, 2019, 56, pp.246-253. 10.1016/j.avsg.2018.07.044 . hal-01903061

\section{HAL Id: hal-01903061}

\section{https://hal-univ-rennes1.archives-ouvertes.fr/hal-01903061}

Submitted on 9 Nov 2018

HAL is a multi-disciplinary open access archive for the deposit and dissemination of scientific research documents, whether they are published or not. The documents may come from teaching and research institutions in France or abroad, or from public or private research centers.
L'archive ouverte pluridisciplinaire $\mathbf{H A L}$, est destinée au dépôt et à la diffusion de documents scientifiques de niveau recherche, publiés ou non, émanant des établissements d'enseignement et de recherche français ou étrangers, des laboratoires publics ou privés. 
1 Impact of an educational intervention on ankle-brachial index performance among

\section{$\underline{\text { medical students and fidelity assessment at month-6 }}$}

3

4 Loukman Omarjee, MD-MSc ${ }^{1,2,3}$, Céline Donnou, $\mathrm{MD}^{1,4}$, Ségolène Chaudru, $\mathrm{MSc}^{2}$, Clara

5 Locher, Pharmd-MSc ${ }^{2}$, Eunice Paul, MD ${ }^{5}$, Marie Charasson, MD ${ }^{1,5}$, Chadi Mauger, MD ${ }^{1}$,

6 Vincent Jaquinandi, MD-PhD ${ }^{1,2}$, Olivier Stivalet, $\mathrm{MD}^{1,2,4}$, Guillaume Mahe, MD-PhD ${ }^{1,2}$

7

8 1: Vascular Medicine Department, CHU de Rennes, 35033 Rennes Cedex 9, France

9 2: Université de Rennes 1, INSERM CIC 1414, 35033 Rennes Cedex 9, France

3: Department of Vascular Medicine, Centre Hospitalier de Redon, 35600 Redon, France

4: Department of Vascular Medicine, Centre Hospitalier de Saint-Malo, 35403 Saint-Malo,

France

5: Department of Vascular Medicine, Centre Hospitalier René Pleven, 22100 Dinan, France

Correspondence to:

\section{Dr Loukman OMARJEE, MD-MSc}

Vascular Medicine Department

Pôle imagerie médicale et explorations fonctionnelles.

Hôpital Pontchaillou, 2 rue Henri Le Guilloux. Rennes, F-35033. France.

Contact Phone Number: +33 (0) 299284321

Contact Mobile Number: +33 (0) 627497051

Contact Email: loukmano@yahoo.fr

Contact Fax Number: +33 (0) 299284364

Twitter: @LoukmanOmarjee 


\section{ABSTRACT}

Background: The resting ankle-brachial index (ABI) is a clinical test to diagnose peripheral artery disease (PAD). The Wyatt's score has been proposed to assess the students' performance on $\mathrm{ABI}$ measurement on a healthy volunteer (HV). No study has shown that this score is sensitive to different teaching methods. In this randomized-controlled-trial, we wanted to determine whether didactic learning alone or didactic learning combined with experiential learning improve proficiency in the ABI procedure assessed by the Wyatt's score.

Methods: Medical students $(n=30)$ received a didactic learning, including i) a presentation of the $\mathrm{ABI}$ guidelines and ii) a video demonstration. Each student, was then randomized into two groups ("the no experiential learning group" and "the experiential learning group"). An initial evaluation was performed after the didactic learning and then the final evaluation at the end of the intervention. A student was considered to be proficient when he performed a correct $\mathrm{ABI}$ procedure on a $\mathrm{HV}$. The correct procedure corresponds to: i) correctly answered Wyatt's score and ii) a difference of an ABI measurement between a professor in vascular medicine and a student $\leq 0.15$.

Results: No student was proficient at the initial evaluation. At the final evaluation, there was a significant difference between the number of proficient students for the Wyatt's score depending on their learning group (didactic alone (1/10) or didactic + experiential training $(15 / 20))$ and also for the ABI procedure (didactic alone (0/10) or didactic + experiential training (16/20)). At month-6, among the twelve students who passed the final evaluation, four passed both the Wyatt's score and the ABI measurement.

Conclusions: Our study demonstrates that the Wyatt's score was sensitive to an educational intervention and no improvement was found in the case of no experiential learning. The Wyatt's score could be used to evaluate student on ABI measurement after an educational intervention. 
52 Trial Registration: A randomized controlled trial (RCT) was conducted in the vascular

53 medicine department of Rennes University Hospital (France). This was approved by the 54 ethics review board of our institution $\left(n^{\circ} 16.150\right)$.

55

56 Keywords: peripheral artery disease, teaching, diagnosis, vascular medicine, medical 57 students

58

Word Count: Abstract: 335; Main Body: 2582

60

List of abbreviations: PAD: Peripheral Arterial Disease; ABI: Ankle-Brachial Index; TASC:

62

63

64

65

66

67

68

69

70

71

72

73

74

75

76

Trans-Atlantic Inter-Society Consensus; AHA: American Heart Association; CVD:

Cardiovascular Diseases; RCT: randomized controlled trial; HV: Healthy Volunteer

(1)

65

6

67

68

69

70

71




\section{BACKGROUND}

Peripheral Arterial Disease (PAD) is a highly debilitating disease that affects 202 million people around the world and about 7 million people in France ${ }^{(1)}$. Noninvasive physiologic vascular studies such as the ankle-brachial index (ABI; ratio of the highest systolic blood pressure measured at the ankle to that measured at the brachial artery) at rest play an important role in the diagnosis and characterization in PAD of the lower extremity ${ }^{(2)}$. ABI is a quick and cost-effective examination in primary care and should be used to screen patients meeting the Trans-Atlantic Inter-Society Consensus Document on Management of PAD (TASC) II criteria ${ }^{(3)}$.

Recent guidelines from the American Heart Association (AHA) have proposed methods for measurement and interpretation of the $\mathrm{ABI}$, as well as the $\mathrm{ABI}$ learning procedure ${ }^{(4)}$. $\mathrm{ABI}$ is measured and calculated as the ratio of the highest systolic blood pressure in each ankle from the right and left posterior tibial or dorsalis pedis arteries, divided by the highest brachial systolic blood pressure. A resting ABI value of 0.90 or less defines PAD diagnosis. Also, ABI is a measure of atherosclerosis severity in the legs and is associated with both atherosclerotic risk factors and prevalent cardiovascular diseases (CVD) in other vascular beds ${ }^{(4)}$. ABI may be used as a risk marker both in the general population with established or free of clinical CV diseases $^{(4)}$. Given the importance of ABI in screening for PAD but also for CVD especially in asymptomatic patients, it is important for vascular physician to know ABI measurement and its interpretation, but above all it requires technical learning to obtain expertise from the beginning of medical studies and to optimize patient care. Previous study of our group has shown in a first randomized trial that didactic learning alone is insufficient to gain proficiency in the ABI procedure and combining didactic learning with experiential learning significantly improved the students' proficiency ${ }^{(5)}$. Moreover, Wyatt et al. have defined a scoring sheet (Wyatt's score) to assess the proficiency in performance of the $\mathrm{ABI}^{(6)}$ (Figure 1). They have 
shown that baseline knowledge of the ABI test was poor among a sample of internal medicine residents and requires action to improve $\mathrm{ABI}$ learning in medical school and residency $\operatorname{programs}^{(6)}$. The aims of this study are to determine i) whether didactic learning alone or didactic learning combined with experiential learning improve proficiency in the ABI procedure assessed by the Wyatt's score, ii) to assess the fidelity of ABI measurement at month-6.

\section{METHODS}

\section{Study design}

A randomized controlled trial (RCT) was conducted in the vascular medicine department of Rennes University Hospital (France). This was approved by the ethics review board of our institution $\left(\mathrm{n}^{\circ}\right.$ 16.150). All included medical students signed an informed consent form and healthy volunteer (HV) and patient cohorts were orally informed according to the approved study procedure.

\section{Didactic Learning}

For this study, $4^{\text {th }}$ to $6^{\text {th }}$ year undergraduate medical students (eighteen women and twelve men), with no prior experience in the evaluation of $\mathrm{ABI}$ received a specific one-hour didactic course provided by an experienced vascular specialist including i) a presentation of the AHA guidelines $(50 \mathrm{~min})^{(4)}$ and ii) a video demonstration of the ABI procedure with a clear description of each step and emphasis on correct technique (10 min). In this video, a vascular specialist performs an ABI measurement on both lower extremities of a patient. The video was recorded to i) explain the utility of the measurement in clinical practice, ii) describe the appropriate care of the Doppler ABI, iii) demonstrate the location of the pulses on the arms 
and lower legs, iv) listen to the quality of the pulse of arterial blood flow, v) list the tips for effectively using the Doppler probe, vi) calculate the $\mathrm{ABI}$, and vii) state the significance of the ABI result.

\section{Baseline assessment}

Following this didactic course, the students were invited to complete the Wyatt's score and perform an $\mathrm{ABI}$ measurement. A technician supervised an initial ABI procedure evaluation. During this evaluation, each medical student attempted to i) perform an ABI measurement for the right or left lower limb extremity of a $\mathrm{HV}$, and ii) select the appropriate numerator and denominator required to calculate the ABI of a hypothetical patient. One minute after the student finished, a vascular specialist blinded to the students' ABI measures came into the examination room and repeated the ABI measurement.

\section{Randomization}

Then, they were randomized into two groups as illustrated in Figure 2 ("no experiential learning group", “experiential learning group"). This latter group was randomly divided into two groups: "experiential learning on HV group" and "experiential learning on patients group".

\section{Educational Intervention}

The HV cohort had no medical risk factor and normal ABIs, whereas the patient cohort consisted of consecutive patients referred for PAD diagnosis. We excluded patients with recent below the knee lower extremity arterial bypass, the presence of open wounds, ulcers, or fistulae contraindicating cuff placement, or who were unable to provide oral informed consent. 
151 For experiential learning on HV, students came three times in pairs for a one-hour session

152 during which students trained on one another. For experiential learning on patients, students

153 came three times individually when a vascular ultrasound exam was programmed. For each

154 experiential learning session, students performed an ABI measurement on both lower

155 extremities (right and left lower extremities) of the volunteer under the vascular specialist's

156 supervision (i.e., seven pressures recorded: right brachial artery, right posterior tibial artery,

157 right dorsalis pedis artery, left posterior tibial artery, left dorsalis pedis artery, left brachial

158 artery and right brachial artery). The equipment provided to the student included adult

159 medium and large sized blood pressure cuffs, an $8 \mathrm{MHz}$ Doppler ultrasound probe, ultrasound

160 gel, a stethoscope, and an automatic blood pressure monitor, as previously reported by Wyatt

161 et $a l^{(6)}$. Students were then instructed to calculate and interpret the ABI, according to the

162 AHA recommendations (i.e., the ABI of each leg should be calculated by dividing the higher

163 of the posterior tibial artery or dorsalis pedis artery pressure by the higher of the right or left

164 arm systolic blood pressure).

165 During each experiential learning session, the vascular specialist identified all problems of the 166 measuring process that may affect the accuracy of the ABI to provide pertinent and 167 personalized feedback to the students. For example, the vascular specialist was careful with 168 the choice or attachment of the cuff, the position and angle of the Doppler probe, or of 169 insufficient contact via the transmission gel for the Doppler probe, which may dislocate 170 during the measurement and deflation of the cuff.

171 Immediately after completion of the ABI measurement, the vascular specialist provided i)

172 feedback to the students on their individual errors in performing the ABI measurement and its

173 calculation and interpretation and ii) a demonstration of the ABI measurement on both lower 174 extremities of the same volunteer. 


\section{Final assessment}

The final assessment was performed following the same procedure as the baseline assessment.

\section{Outcome measures}

A student was considered to be proficient in performing the ABI measurement if he correctly answered the 15-items of the Wyatt's score and performed the following procedure during the evaluation on a HV: i) installed the volunteer in a supine position with the head and heels supported, ii) used the appropriate device among the equipment provided for each participant (i.e., sphygmomanometer cuff with a width of a least $40 \%$ of the limb circumference placed just above the malleoli, $8 \mathrm{MHz}$ Doppler probe with Doppler gel applied over the probe and placed in the area of the pulse at a $45^{\circ}$ to $60^{\circ}$ angle to the surface of the skin), iii) inflated the cuff progressively up to $20 \mathrm{mmHg}$ above the level of flow signal disappearance and then deflated slowly to detect the pressure level of flow signal reappearance, iv) performed the pressure measurements in the accurate order (i.e. for the right $\mathrm{ABI}$ measurement: right brachial artery, right posterior tibial artery, right dorsalis pedis artery, left brachial artery, and right brachial artery again), v) recorded each pressure, vi) selected the appropriate numerator and denominator to calculate the $\mathrm{ABI}$, and vii) obtained an accurate $\mathrm{ABI}$. Even if the $\mathrm{ABI}$ of the student was accurate, but the pressure measurements were not performed in the correct order, or the sphygmomanometer cuff was not correctly placed, the student was not considered to be proficient.

An ABI was considered to be accurate if the difference between the ABIs measured by the vascular specialist and the student was $\leq 0.15$, as previously reported ${ }^{(7,8)}$. Furthermore, this cut-off was chosen since a decrease of the $\mathrm{ABI}>0.15$ over time is effective for detecting significant PAD progression, as stated in the AHA recommendations ${ }^{(4)}$. The intra-observer 
coefficient of variation for the ABI in our vascular laboratory is $8 \%$ (Typical error of the estimate is 0.06$)$.

\section{Fidelity assessment at month-6}

Between the beginning of the study and the evaluation at day-28, only the students of the group "experiential learning group" received the 3 sessions of practical training. Between the end of the evaluation and the follow-up at month-6, no student received practical training.

Students considered proficient having passed all the theoretical and practical tests at the final assessment were invited to perform another evaluation at month- 6 in order to verify the acquisition of knowledge and skills of measuring the ABI.

\section{Statistical analysis}

Statistical analysis was performed using the computing environment R (R Development Core Team, 2005). A Fischer test was used to compare the number of students proficient in performing the Wyatt's score and ABI procedure in each group between the initial and final evaluations. At month-6, the percentage of success was calculated for the Wyatt's score and the $\mathrm{ABI}$ procedure according to the randomization group of each student.

Between-group comparisons were also performed at the initial and final evaluations. A twotailed $\mathrm{p}$ value $<0.05$ was considered to be statistically significant.

\section{RESULTS}

Thirty medical students were included in this RCT (Figure 2) where they are completed the baseline Wyatt's score and performed ABI assessment. Of the initial cohort of 30 students, 20 $(67 \%)$ were randomized in two groups of 10 and received the educational intervention. One 
group performed the three times repeat assessment on HV while another one performed it on patients.

At the initial evaluation, after the didactic learning alone, no student was proficient in performing the ABI procedure while 2 (6.7\%) passed the Wyatt's score.

At the final evaluation, the number of proficient students for the Wyatt's score in the no training group was not significantly improved compared with the initial evaluation $(1 / 10 \mathrm{vs}$ 1/10; $\mathrm{p}=\mathrm{ns}$; Figure 3, panel A). The same results were observed for the ABI procedure in this group (1/10 vs 2/10; $\mathrm{p}=\mathrm{ns}$; Figure 3, panel B). In the experiential learning group (training on HV), the number of proficient students for the Wyatt's score significantly increased (0/10 vs 9/10; $\mathrm{p}<0.001$; Figure 3, panel A) and also for the ABI procedure $(0 / 10$ vs $8 / 10 ; p<0.001$; Figure 3, panel B) after three experiential ABI measurements on both lower extremities (right and left). In the experiential learning group (training on patient), the number of proficient students for the Wyatt's score was not significantly improved ( $1 / 10$ vs $6 / 10 ; p=0.07$; Figure 3, panel A) while for the ABI procedure, it was significantly improved (0/10 vs 8/10; $p<0.001$; Figure 3, panel B) after three experiential ABI measurements on both lower extremities (right and left).

At the final evaluation, there was a significant difference between the number of proficient students for the Wyatt's score depending on their learning group (didactic alone (1/10) or didactic + experiential training $(15 / 20))$ and also for the ABI procedure (didactic alone $(0 / 10)$ or didactic + experiential training (16/20)). There was no significant difference in the proficiency of the students according to their experiential learning group affiliation (HV vs patients).

\section{Fidelity at month-6}


At the final evaluation, only 1 student in the no training group was successful, while in the experiential learning group, 6 students from the training on HV group and 5 from the training on patient group were successful. At month-6, the student of the no training group failed. In the group receiving the interventional education, $3 / 5(60 \%)$ passed the Wyatt's score and 1/5 (20\%) the ABI procedure in the training on patient group. 5/6 (83\%) passed the Wyatt's score and $3 / 5(60 \%)$ the ABI procedure in the training on HV group. (Figure 4)

\section{DISCUSSION}

$\mathrm{ABI}$ is an important and widely non-invasive used tool for the diagnosis of PAD and is part of the medical curriculum. In this we showed that i) didactic learning alone (no training), even with a video demonstration, is insufficient to ensure proficiency of medical students in performing the Wyatt's score and the ABI procedure; ii) didactic learning associated with an intervention that combined three experiential training sessions with direct feedback to participants significantly improved the students' proficiency relative to didactic learning alone for both Wyatt's score and ABI procedure; iii) at month-6, there is no fidelity for the only one student who passed the final evaluation while in the experiential group, the fidelity decreased more for the ABI procedure than the Wyatt's score leading the need for continuous training.

Our study demonstrates that the Wyatt's score was sensitive to an educational intervention and no improvement was found in case of no experiential learning. Therefore, the Wyatt's score could be used for the assessment of vascular medicine students. It should be of interest to validate it among PAD patients.

Teaching of the ABI procedure in major medical schools consists of only a didactic session, evaluated by questionnaire ${ }^{(9-11)}$, that is insufficient to ensure competence with the theoretical procedure. Our study supports dropping didactic learning alone or combining it with 
experiential training. Training should include practical instruction on how to perform an ABI but also a didactical teaching following the international recommendation ${ }^{(4)}$.

There was no difference in student proficiency between the two experiential learning modalities (HV vs patients). Thus, experiential learning on HV may be preferable from a practical point of view (i.e. organization, feasibility) as a first step of teaching the ABI procedure.

The strength of this study is that we used the ABI measurement value of our vascular specialists as a "gold standard" for comparison with the measurements performed by the students.

\section{Limitations}

This study had some limitations. First, students in the no training group received only one hour of didactic learning. It cannot be excluded that repeat didactic learning might have improved the final proficiency of the students in completing the Wyatt's score and measuring the ABI. However, following only one didactic course corresponds to a current practice in most French medical schools ${ }^{(12)}$. The present study confirms that such learning is insufficient and experiential training should be performed, as suggested by other studies ${ }^{(13,14)}$.

\section{CONCLUSION}

Didactic learning alone is insufficient for proficiency in performing the Wyatt's score and $\mathrm{ABI}$ procedure on $\mathrm{HV}$; it should be combined with experiential learning.

The Wyatt's score could be used to evaluate student on ABI measurement after an educational intervention. In case of success of the Wyatt's score, an ABI done by an expert is not required. Nevertheless, without continuous practice, we note that at month-6, the theoretical knowledge on the Wyatt's score as well as the skills for the measurement of the ABI do not 
297 persist Further studies are needed to i) determine the minimal amount of experiential learning

298 required to be proficient; ii) assess the effect of experiential learning modalities (HV vs

299 patient) on a larger population; and iii) evaluate the students' proficiency in a follow-up

300 study.

301 Acknowledgments

302 The authors thank Awenig Carel, Marielle Delalande, Virginie Jégou, Philippe Landreau, and

303 Mathilde Ouvrard for their technical help. Ségolene Chaudru, a PhD student of our team, has

304 received a grant from the region "Bretagne" (Bourse ARED).

305

306 Competing Interests

307 The authors declared no potential conflicts of interest with respect to the research, authorship,

308 and/or publication of this article.

309

$310 \quad$ Funding

311 The authors received no financial support for the research, authorship, and/or publication of

312 this article.

\section{Availability of data and materials}

The datasets used and/or analysed during the current study available from the corresponding author on reasonable request.

\section{Permission Information}

319 The authors do hereby declare that all illustrations and Figures in the manuscript are entirely original and do not require reprint permission. 


\section{Contributors}

Dr Loukman OMARJEE contributed to literature search, data collection, data analysis, data interpretation, writing the report and final approval of the version to be published.

Dr Céline DONNOU contributed to literature search, data analysis, data interpretation, revising the intellectual content and final approval of the version to be published.

Ms Ségolène CHAUDRU contributed to study management, literature search, data analysis, data interpretation, revising the intellectual content and final approval of the version to be published.

Dr Clara LOCHER contributed to literature search, data analysis, data interpretation, revising the intellectual content and final approval of the version to be published.

Dr Marie CHARASSON contributed to literature search, data analysis, data interpretation, revising the intellectual content and final approval of the version to be published.

Dr Chadi MAUGER contributed to literature search, data collection, data analysis, data interpretation, revising the intellectual content and final approval of the version to be published.

Dr Vincent JAQUINANDI contributed to literature search, data collection, data analysis, data interpretation, revising the intellectual content and final approval of the version to be published.

Dr Olivier STIVALET contributed to literature search, data collection, data analysis, data interpretation, revising the intellectual content and final approval of the version to be published.

Pr Guillaume MAHE contributed to study design, literature search, data collection, data analysis, data interpretation, revising the intellectual content and final approval of the version to be published. 


\section{Ethics approval and consent to participate}

348 Ethical approval of the study was obtained from the Ethic Committee of the Rennes

349 University Hospital (France) and approved by the institutional review board (IRB) $\left(\mathrm{n}^{\circ}\right.$ 16.150). All included medical students signed an informed consent form and HV and patient

351 cohorts were orally informed according to the approved study procedure.

352 All procedures contributing to this work comply with the ethical standards of the relevant

353 national and institutional committees on human experimentation and with the Helsinki

354 Declaration of 1975 , as revised in 2008. The objectives of the study were explained to the participants who were informed that their participation was voluntary, and anonymity was 356 assured. 


\section{REFERENCES}

1. Fowkes FGR, Rudan D, Rudan I, Aboyans V, Denenberg JO, McDermott MM, et al. Comparison of global estimates of prevalence and risk factors for peripheral artery disease in 2000 and 2010: a systematic review and analysis. Lancet Lond Engl. 2013 Oct 19;382(9901):1329-40.

2. Sibley RC, Reis SP, MacFarlane JJ, Reddick MA, Kalva SP, Sutphin PD. Noninvasive Physiologic Vascular Studies: A Guide to Diagnosing Peripheral Arterial Disease. Radiogr Rev Publ Radiol Soc N Am Inc. 2017 Feb;37(1):346-57.

3. Lau JF, Weinberg MD, Olin JW. Peripheral artery disease. Part 1: clinical evaluation and noninvasive diagnosis. Nat Rev Cardiol. 2011 May 31;8(7):405-18.

4. Aboyans V, Criqui MH, Abraham P, Allison MA, Creager MA, Diehm C, et al. Measurement and Interpretation of the Ankle-Brachial Index: A Scientific Statement From the American Heart Association. Circulation. 2012 Dec 11;126(24):2890-909.

5. Donnou C, Chaudru S, Stivalet O, Paul E, Charasson M, Selli J-M, et al. How to become proficient in performance of the resting ankle-brachial index: Results of the first randomized controlled trial. Vasc Med Lond Engl. 2017 Noy 1;1358863X17740993.

6. Wyatt MF, Stickrath C, Shah A, Smart A, Hunt J, Casserly IP. Ankle-brachial index performance among internal medicine residents. Vasc Med Lond Engl. 2010 Apr;15(2):99105.

7. Monti M, Calanca L, Alatri A, Mazzolai L. Accuracy of in-patients ankle-brachial index measurement by medical students. Vasa. 2016 Feb;45(1):43-8.

8. Ray SA, Srodon PD, Taylor RS, Dormandy JA. Reliability of ankle:brachial pressure index measurement by junior doctors. Br J Surg. 1994 Feb;81(2):188-90.

9. Chaudru S, de Müllenheim P-Y, Le Faucheur A, Kaladji A, Jaquinandi V, Mahé G. Training to Perform Ankle-Brachial Index: Systematic Review and Perspectives to Improve Teaching and Learning. Eur J Vasc Endovasc Surg Off J Eur Soc Vasc Surg. 2015 Oct 23;

10. Chaudru S, de Müllenheim P-Y, Le Faucheur A, Jaquinandi V, Kaladji A, Mahe G. Knowledge about ankle-brachial index procedure among residents: being experienced is beneficial but is not enough. VASA Z Gefasskrankheiten. 2016 Jan;45(1):37-41.

11. Chaudru S, de Müllenheim P-Y, Le Faucheur A, Jaquinandi V, Mahé G. Ankle brachial index teaching: A call for an international action. Int J Cardiol. 2015 Apr 1;184:48991.

12. Mahé G. [Ankle-brachial index measurement: Methods of teaching in French medical schools and review of literature]. J Mal Vasc. 2015 May;40(3):165-72.

13. Wyatt MF, Stickrath C, Shah A, Smart A, Hunt J, Casserly IP. Ankle brachial index 
407 performance among internal medicine residents. Vasc Med. 2010 Apr 1;15(2):99-105.

408 14. Georgakarakos E, Papadaki E, Vamvakerou V, Lytras D, Tsiokani A, Tsolakaki O, et

409 al. Training to Measure Ankle-Brachial Index at the Undergraduate Level: Can It Be 410 Successful? Int J Low Extrem Wounds. 2013 Jun 1;12(2):167-71.

411

412

413

414

415

416

417

418

419

420

421

422

423

424

425

426

427

428

429

430

431

432

433

434 
435

436

437

438

439

440

441

442

Figure titles:

Figure 1: Wyatt's Score

Figure 2: Study design flow chart

Figure 3, panel A: Wyatt's score evaluation

Figure 3, panel B: ABI measurement on healthy volunteers

Figure 4: Fidelity assessment at month-6

\section{Figure legends:}

Figure 1: Wyatt's Score for Ankle-brachial index measurement

Figure 2: Study design flow chart. ABI: Ankle-brachial index $\mathrm{X}$ : number of students proficient at the final assessment $(\mathrm{T} 0+28$ days on average)

Figure 3: Comparison of the number of medical students proficient in performing the Wyatt's score (Panel A) and resting ABI (Panel B) procedure on healthy volunteers at the initial and final evaluation between the the 'no training group', the 'experiential learning group training on healthy volunteer' and the 'experiential learning group training on patients'

Figure 4: Percentage of success of medical students proficient at the final evaluation in performing the Wyatt's score and resting ABI procedure on healthy volunteers at month-6 between the 'no training group', the 'experiential learning group training on healthy volunteer' and the 'experiential learning group training on patients'. 


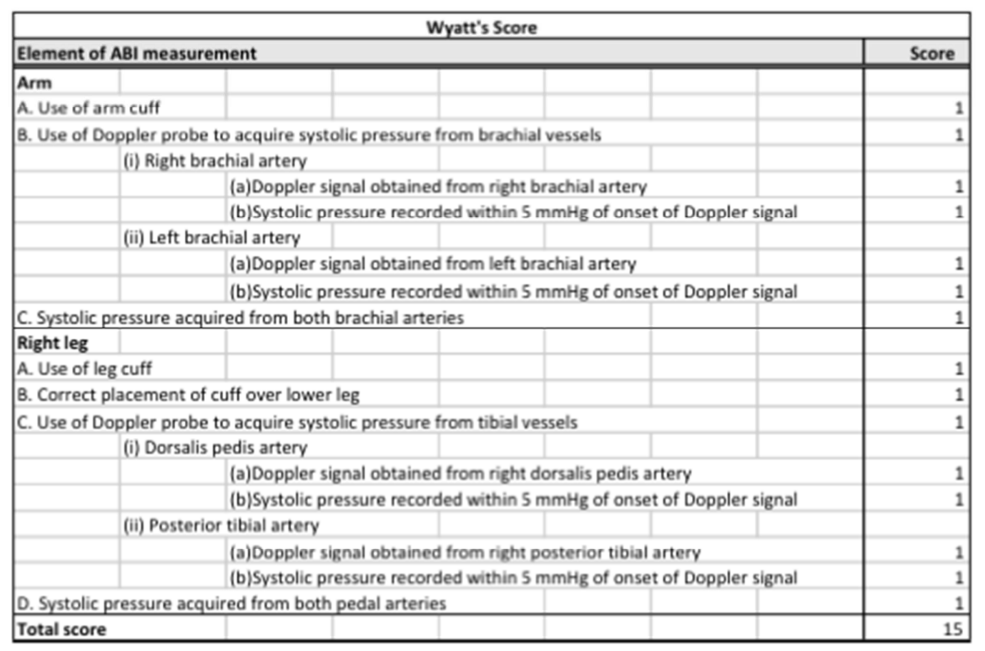




\section{DIDACTIC LEARNING}

(C) Didactic learning provided by an experienced vascular specialist including:

- Presentation of the AHA guidelines for ABI measurement and interpretation;

- Video demonstration of ABI procedure

\begin{tabular}{|l|l|}
\hline & BASELINE ASSESSMENT $\left(\mathbf{T}_{0}\right)$ \\
\hline $\mathrm{n}=30$ & On a healthy volunteer \\
"Complete the Wyatt's questionnaire and perform an ABI measurement for the right or left lower extremity \\
of the subject and select the appropriate numerator and denominator required to calculate the ABI "
\end{tabular}

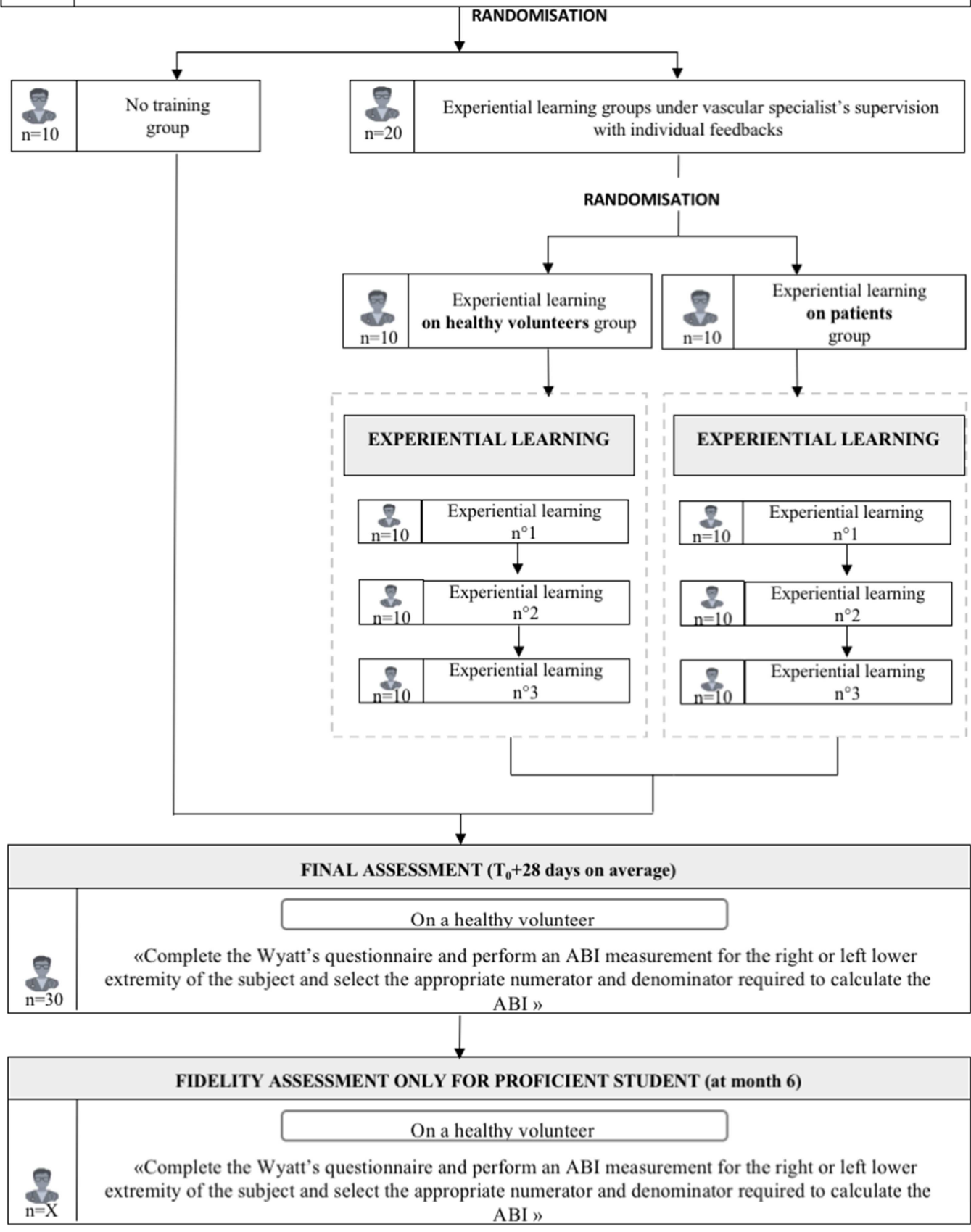


A

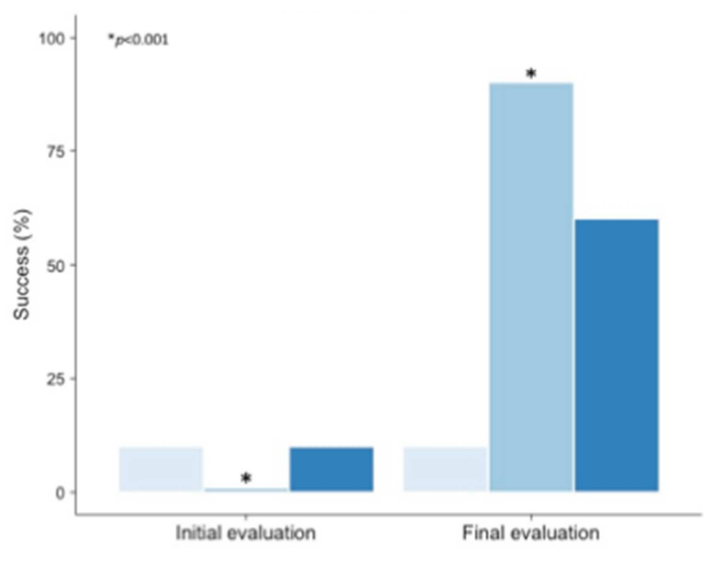

No training Training on healthy volunteer Training on patient
B

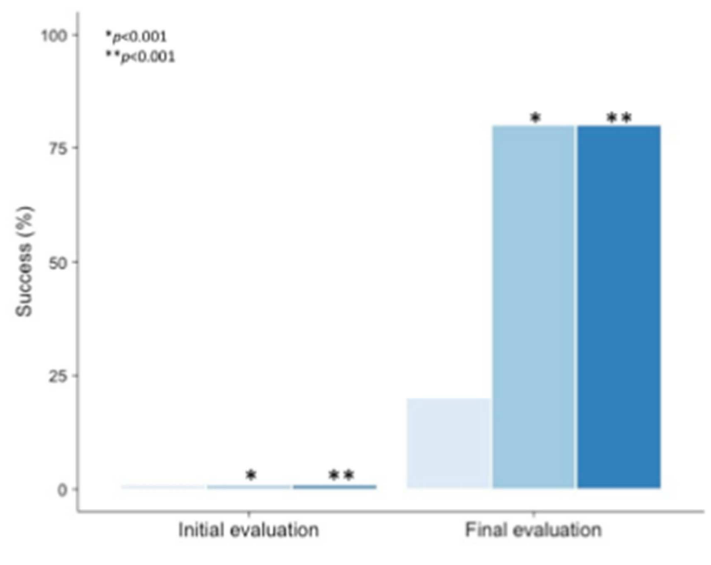

No training Training on healthy volunteer Training on patient 


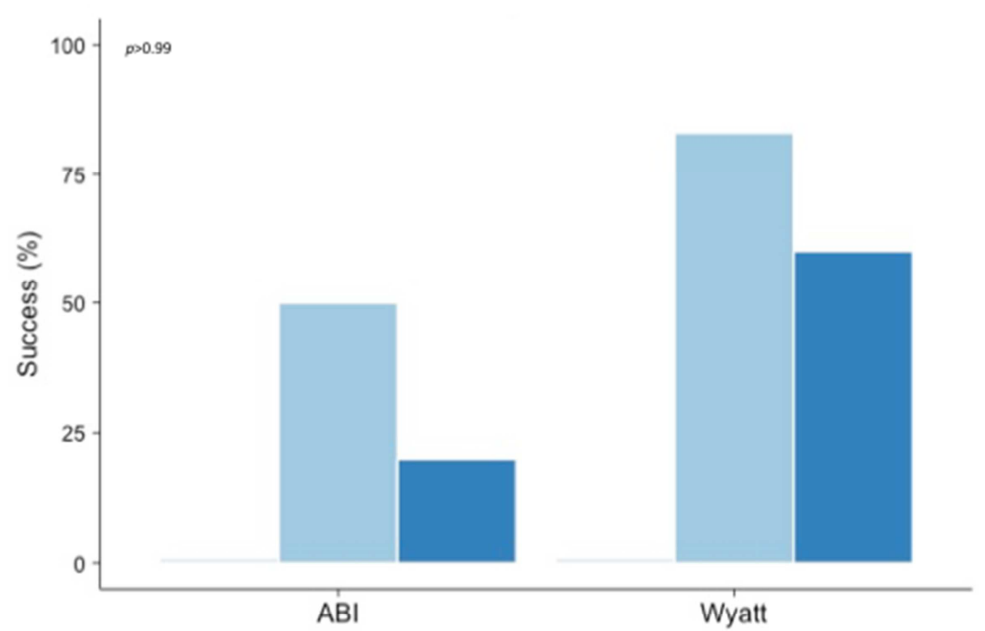

No training Training on healthy volunteer $\quad$ Training on patient 